This year has proven to be a veritable cliff-hanger for the world of biomedicine. At the same time that the US government stands poised on the brink of the so-called 'fiscal cliff', pharmaceutical companies are stumbling with the industry's 'patent cliff' and academic researchers face the looming 'funding cliff'. But not everything in 2012 was so dire, with dozens of new drugs to hit worldwide markets and countless discoveries made to enable the next generation of medicines. What follows are a set of 'Cliff's notes' to the year that was for the field.

\title{
Timeline of events: A brief history of what made news this year
}

\begin{abstract}
Brain gain: The US Department of Health and Human Services published a draft framework on 9 January laying out a national plan for fighting Alzheimer's disease. The document, which was finalized in May 2012, calls for effectively preventing and treating the disorder by 2025. A month later, the EU's Joint Programme in Neurodegenerative Disease Research launched a strategy to improve coordination between research and funding efforts on such diseases.
\end{abstract}

Grounded: Medical research organizations in the UK warned on 14 March that research could be disrupted because ferry companies had banned the transport of laboratory animals in response to pressure from animal rights groups. Similar animal rights campaigns around the world have led all but a few airlines to halt flights for research primates over the past two years, and three major air cargo carriers said this year that they would no longer ship any mammals whatsoever.

Regulatory revival: In the wake of two recent scandals of medical product oversight, French authorities disbanded the country's Health Products Safety Agency (AFSSAPS) and replaced it with a new body, the National Agency for the Safety of Medicines and Health Products (ANSM) on 1 May. The new agency's mandate includes extending its scope to conduct research into the risks and benefits of new medicines and tightening conflict-of-interest rules.

Surveillance SNAFU: The New York Times broke a story on 14 July revealing that the US Food and Drug Administration (FDA) had spied on several of its disgruntled staff scientists in an effort to prevent the release of negative information about the agency. In the course of monitoring the would-be whistleblowers' communication with reporters, government officials and outside researchers, a contractor working with the agency erroneously posted thousands of private e-mails and proprietary information on the design of medical devices to a public website.

Hand in hand: Ten major pharmaceutical companies have made a pact to cooperate on efforts to revive flagging drug discovery efforts. TransCelerate Biopharma, a nonprofit organization jointly launched by the drugmakers on 19 September and headed by Garry Neil, a former vice-president of science and technology at Johnson \& Johnson, will start by standardizing clinical trial protocols and data collection to make drug testing more efficient.
Off the map: The World Health Organization (WHO) on 25 February removed India from its list of polio-endemic countries after no new cases were detected in 12 months. The WHO later kicked off a reinvigorated vaccination program in Pakistan, Nigeria and Afghanistan, the three countries remaining on the list. However, Taliban interference with the vaccination campaign has blocked progress in Pakistan.

Publish and perish? The US government on April $\mathbf{2 0}$ formally accepted the recommendation of its National Science Advisory Board for Biosecurity (NSABB) to proceed with the publication of edited versions of two papers that described how to make the $\mathrm{H} 5 \mathrm{~N} 1$ avian influenza virus more transmissible. The NSABB's advice to publish was a reversal of its widely criticized recommendation, made late last year, that the studies' methods sections be redacted for fear the information could be used for nefarious purposes.

Eggs-istential debate: Reproductive techniques in which genetic material from a faulty egg is transferred to a healthy one are ethical as long as they are deemed safe, the Nuffield Council on Bioethics in the UK advised on 11 June. Such techniques, which involve a controversial egg manipulation method called nuclear transfer, are currently forbidden under UK law, but their legality is under review because lab experiments have shown that they can prevent the transmission of mitochondrial diseases.

Patently valid: A US appeals court on 16 August upheld a legal decision reached last year that concluded that patents on variants of the breast and ovarian cancer genes BRCA1 and

A $B R C A 2$, held by Myriad Genetics, were valid. The reexamination was prompted by a US Supreme Court ruling in March, in which two patents for determining drug dosage, held by medical diagnostics company Prometheus Laboratories, were deemed invalid because they reflected a natural process.

Shot in the back: US authorities on $\mathbf{2 3}$ October began a criminal investigation into the practices of the New England Compounding Center, the Massachusetts pharmacy whose contaminated drugs caused a multistate fungal meningitis outbreak that resulted in at least 490 illnesses and 34 deaths. The FDA claimed that a tangle of regulations left the agency with little authority over compounding pharmacies. Democratic Senator Tom Harkin of lowa vowed to develop federal legislation for tighter oversight.

Gesundheit: Two of Berlin's largest biomedical institutes teamed up on $\mathbf{6}$ November to create the Berlin Institute of Health, a new clinical research center designed to tackle a broad spectrum of diseases. With at least $€ 320$ million ( $\$ 405$ million) in new funding over five years as well as state-of-the-art clinical and molecular facilities, officials hope the new institute will provide a draw for world-class research talent. 